\title{
Formulation and In-vitro Evaluation of Bilayer Tablets of Atenolol and Amlodipine
}

\author{
K. M. Yasif Kayes Sikdar, Ahad Ahamed, Md. Mahbubul Alam, \\ Md. Raihan Sarkar and B. K. Sajeeb
}

Department of Pharmaceutical Technology, Faculty of Pharmacy, University of Dhaka Dhaka-1000, Bangladesh

(Received: February 20, 2019; Accepted: February 26, 2019; Published: July 22, 2019)

\begin{abstract}
The present investigation was focused on formulation and in-vitro evaluation of a fixed dose bilayer tablet of two prominent antihypertensive agents, atenolol and amlodipine. The tablets were designed to immediately release atenolol (ATF1-ATF5) by using different percentage of sodium starch glycolate as super-disintegrant for prompt blood pressure lowering activity and sustain release amlodipine (AMF1AMF5) by varying the percentage of hydroxy propyl methylcellulose (HPMC) for prolonged activity. After evaluation of the physical and chemical parameters of the formulations according to United States Pharmacopoeia (USP) guidelines, the best immediate release formulation was found in ATF1 in terms of dissolution (99.87\% after 45 minutes) and other tablet properties like hardness, disintegration time, good flow properties etc. However, the best sustained release activity was found in AMF3 in terms of dissolution (99.98\% after 24 hours with constant release) and other tablet properties. After optimization of the formulations, both atenolol and amlodipine parts were successfully compressed into bilayer tablets and post-compression parameters were evaluated. In $0.1 \mathrm{~N} \mathrm{HCl}$ medium, the release of atenolol from bilayer tablet was found $98.97 \%$ after 45 minutes and in case of amlodipine it was found $98.12 \%$ in $0.1 \mathrm{~N} \mathrm{HCl}$ medium followed by phosphate buffer medium after 24 hours. Drug release kinetics showed that the atenolol layer followed Case I, QasiFickian transport and amlodipine layer followed Anomalous (non-Fickian) transport. Compatibility study was conducted by using Fourier Transform Infrared Spectroscopy (FTIR) and Differential Scanning Calorimetry (DSC). Moreover, crystalline nature of substances and extent of its conversion to amorphous form was studied using X-ray Diffractometry (X-RD).
\end{abstract}

Key words: Bilayer tablet, antihypertensive agents, atenolol, amlodipine.

\section{Introduction}

The goal of any drug delivery system is to provide a therapeutic amount of drug to the proper site in the body to achieve and maintain desired drug concentration. Combination products are two or more active drug substances in a single dosage form, which provide the advantages of combination therapy in patients with chronic conditions like hypertension, while reducing the number of prescriptions and the attendant administrative costs with improving patient compliance (Bangalore et al., 2007). Clinically, combination therapy in hypertension treatment involves two or more drugs from different classes can result in better drug efficacy and is recommended for initial stage of hypertension treatment (Chobanian et al., 2003). The combination of atenolol and amlodipine significantly decreases and stabilize blood pressure and systolic blood pressure variability through their synergistic effect (Xu et al., 2004).

Atenolol is a selective beta-adrenergic receptor blocking agent without membrane stabilizing or intrinsic sympathomimetic activities. At higher doses,

Correspondence to: K. M. Yasif Kayes Sikdar; E-mail: yasif@du.ac.bd

DOI: https://doi.org/10.3329/bpj.v22i2.42299 
it inhibits beta-adrenoreceptors, chiefly located in the bronchial and vascular musculature (Brown et al., 1976) whereas, amlodipine is a dihydropyridine calcium antagonist that inhibits the transmembrane influx of calcium ions into vascular smooth muscle and cardiac muscle. Thus, through vasodilatation it causes a decrease in peripheral vascular resistance, which results in reduction in blood pressure (Spedding and Paoletti, 1992). Both beta-blockers and dihydropyridine calcium antagonist are widely used in the treatment of hypertension. Therefore, their combination is a logical choice for neutralizing the side effects of each drug and to control blood pressure.

Bilayer tablets have been developed to achieve controlled delivery of different drugs in a single dosage form with predefined release profiles to promote patient convenience and compliance. Moreover, avoiding chemical incompatibilities between active pharmaceutical ingredients (API) by physical separation was a prime focus for developing this formulation technique. Despite their advantages, due to the use of different materials and complex geometric boundaries between the adjacent layers, the mechanical structures of this drug delivery system have become quite intricate, requiring complicated yet patient friendly tablet design. Several pharmaceutical companies are currently developing bilayer tablets for a variety of reasons such as patent, therapeutic and marketing extension to reduce capital investment by using modified tablet presses to develop and produce such tablets.

So, the aim of the present research work was to formulate and evaluate orally ingested bilayer tablets of atenolol and amlodipine to release atenolol immediately as well as to sustain the release of amlodipine up to 24 hours to enhance the oral bioavailability by individual optimized formulation.

\section{Materials and Methods \\ Materials}

Atenolol and amlodipine were obtained as gift samples from Beximco Pharmaceuticals Ltd. microcrystalline cellulose (Type-101) was procured from JRS Pharma GmbH, Germany, Povidone K-30 was purchased from ISP Sales, UK. Sodium starch glycolate and magnesium stearate were bought from MERCK, Germany. Diabasic calcium hydrogen phosphate was purchased from Chemische Fabrik Budenheim, Germany. Hydroxy propyl methylcellulose (HPMC) (Hypromellose 2208 K-100 premium) and FD\&C Yellow 6 were bought from Colorcon Asia private limited, India.

Equipment: Electronic balance and moisture analyzer of Metlar Toledo, Japan, micromix high shear mixer granulator and blender with dry granulator of Dec, USA, rapid dryer, stability chamber and oven of BMT, USA, IMA Killian tablet compression machine of Romaco Pharmatechnik $\mathrm{GmbH}$, Germany, hardness tester of Erweka GmbH, Germany, friability tester, USP disintegration test apparatus, tap density tester and USP dissolution apparatus II of Electrolab, India, double beam UVspectrophotometer and High Performance Liquid Chromatography (HPLC) of Shimadzu, Japan, Fourier Transform Infrared Spectroscopy (FTIR) machine of PerkinElmer, USA were used to perform the research work.

\section{Methods}

Characterization of immediate release (IR) and sustain release (SR) granules: Both IR and SR granules were evaluated for various pre-compression parameters. LOD was measured only for atenolol granules as amlodipine tablets were prepared by dry granulation technique. Angle of repose was measured by fixed funnel method. Bulk and tapped densities were determined by tapped density apparatus from which compressibility index and Hausner's ratio values were calculated according to the USP guideline.

Evaluation of drug-excipient compatibility study in stability chamber: Compatibility studies of both atenolol and amlodipine with probable excipients to be used were conducted through both individual and binary mixture of APIs and excipients as well as both formulation blends were prepared and packaged in glass vials and sealed with rubber stopper and Low- 
Density Polyethylene (LDPE) plug. These samples were incubated at room condition $\left(25{ }^{\circ} \mathrm{C} \pm 2{ }^{\circ} \mathrm{C} \&\right.$ $60 \% \pm 5 \% \mathrm{RH})$, accelerated condition $\left(40{ }^{\circ} \mathrm{C} \pm 2{ }^{\circ} \mathrm{C}\right.$ $\& 75 \% \pm 5 \% \mathrm{RH})$ and dry heat condition, $50{ }^{\circ} \mathrm{C}$ for one month. The LDPE plugs were punctured for samples of accelerated condition $\left(40{ }^{\circ} \mathrm{C} \pm 2{ }^{\circ} \mathrm{C}\right.$ \& $75 \% \pm 5 \%$ RH) (Charoo et al., 2012).

Drug-excipient compatibility studies by FTIR and DSC: The compatibility of drugs with their respective excipients were studied by FTIR spectroscopy. The scanning was performed 20 times for both atenolol and amlodipine with resolution of 1 $\mathrm{cm}^{-1}$ over the region of $4000-400 \mathrm{~cm}^{-1}$. The scans were evaluated for the presence of principle peaks of drug, shifting and masking of drug peaks and appearance of new peaks due to polymer interaction. DSC is a reliable method to screen drug excipients compatibility and provides maximum information about possible interactions. A sharp endothermic peak at any temperature indicates the melting point of drug. In formulation mixer, sharp endothermic peak at any temperature indicating the stability of the formulation up to that temperature (Pereira et al., 2007; Silva et al., 2015; Moisei et al., 2014).

Evaluation of polymorphic change by $X-R D$ : Degree of crystallinity is one of the factors influencing the solubility and dissolution rate of a drug substance. Hence, crystalline nature of a substance and extent of its conversion to amorphous form was studied by X-Ray Diffractometry (X-RD).

Formulation development of immediate release atenolol tablets: Total 5 (five) formulations (ATF1, ATF2, ATF3, ATF4 and ATF5) were prepared by varying the amount of the povidone K-30 and sodium starch glycolate. One factor at a time (OFAT) design was followed in each formulation. In formulation ATF1, ATF2 and ATF3, amount of sodium starch glycolate was remained constant (5\%) where povidone K-30 amount was varied (3\%, $1 \%$ \& 5\% respectively). In formulations ATF1, ATF4 and ATF5, amount of povidone K-30 was remained constant and sodium starch glycolate amount was varied $(5 \%, 3 \%$ and $1 \%$ respectively). The formulations are listed in table 1.

Table 1. Formulation design of atenolol immediate release tablets.

\begin{tabular}{|c|c|c|c|c|c|c|c|c|c|c|c|c|}
\hline \multirow[t]{2}{*}{$\begin{array}{l}\text { Formulation } \\
\text { code }\end{array}$} & \multicolumn{2}{|c|}{$\begin{array}{l}\text { Atenolol } \\
(\mathrm{mg})\end{array}$} & \multicolumn{2}{|c|}{$\begin{array}{l}\text { Microcrystalline } \\
\text { cellulose } \\
\text { (Type- } 101)(\mathrm{mg})\end{array}$} & \multicolumn{2}{|c|}{$\begin{array}{l}\text { Povidone K-30 } \\
\text { (mg) }\end{array}$} & \multicolumn{2}{|c|}{$\begin{array}{l}\text { Sodium starch } \\
\text { glycolate } \\
(\mathrm{mg})\end{array}$} & \multicolumn{2}{|c|}{$\begin{array}{l}\text { Magnesium } \\
\text { stearate } \\
(\mathrm{mg})\end{array}$} & \multicolumn{2}{|c|}{$\begin{array}{c}\text { Total tablet } \\
\text { weight }(\mathrm{mg})\end{array}$} \\
\hline & $\begin{array}{l}\text { Qty/ } \\
\text { Tab }\end{array}$ & $\%$ & $\begin{array}{l}\text { Qty/ } \\
\text { Tab }\end{array}$ & $\%$ & $\begin{array}{l}\text { Qty/ } \\
\text { Tab }\end{array}$ & $\%$ & $\begin{array}{l}\text { Qty/ } \\
\text { Tab }\end{array}$ & $\%$ & $\begin{array}{l}\text { Qty/ } \\
\text { Tab }\end{array}$ & $\%$ & $\begin{array}{l}\text { Qty/ } \\
\text { Tab }\end{array}$ & $\%$ \\
\hline ATF1 & 50 & 33.33 & 86.5 & 56.67 & 4.5 & 3 & 7.5 & 5 & 1.5 & 1 & 150 & 100 \\
\hline ATF2 & 50 & 33.33 & 89.5 & 59.67 & 1.5 & 1 & 7.5 & 5 & 1.5 & 1 & 150 & 100 \\
\hline ATF3 & 50 & 33.33 & 83.5 & 55.67 & 7.5 & 5 & 7.5 & 5 & 1.5 & 1 & 150 & 100 \\
\hline ATF4 & 50 & 33.33 & 89.5 & 59.67 & 4.5 & 3 & 4.5 & 3 & 1.5 & 1 & 150 & 100 \\
\hline ATF5 & 50 & 33.33 & 83.5 & 61.67 & 4.5 & 3 & 1.5 & 1 & 1.5 & 1 & 150 & 100 \\
\hline
\end{tabular}

Immediate release layer of atenolol (ATF1ATF5) were prepared by wet granulation method following the formulation given in table 1. Atenolol and other excipients like microcrystalline cellulose (Type-101), and povidone K-30 were accurately weighed and sifted through a mesh screen of \#30 and kept in a polybag and mixed. Sodium starch glycolate was passed through a mesh screen of \#40 and added to the mixer. The mixer was taken in the micromix high shear mixer granulator \& dry mixed for 10 minutes at $15 \mathrm{rpm}$. After that approximately $60 \mathrm{ml}$ purified water was added as granulating agent. Sufficient water was added for proper granulation. After milling, adjusted quantity of magnesium stearate was dispensed and sieved through sieve \#40 and added to the milled granules and blended for 3 
minutes at $15 \mathrm{rpm}$. Then the granules were compressed into tablets. The physicochemical parameters of atenolol tablets (e.g. weight variation, friability, diameter, thickness, hardness and disintegration time) were measured (Ryakala et al., 2015).
Formulation development of sustained release amlodipine tablets: A total of 5 (five) formulations (AMF1, AMF2, AMF3, AMF4 and AMF5) were prepared by varying the amount of the HPMC are listed in table 2.

Table 2. Formulation design of amlodipine sustained release tablets.

\begin{tabular}{|c|c|c|c|c|c|c|c|c|c|c|c|c|c|c|}
\hline \multirow[t]{2}{*}{$\begin{array}{c}\text { Formu- } \\
\text { lation } \\
\text { code }\end{array}$} & \multicolumn{2}{|c|}{$\begin{array}{c}\text { Amlodipine } \\
\text { besylate } \\
(\mathrm{mg})\end{array}$} & \multicolumn{2}{|c|}{$\begin{array}{l}\text { Anhydrous } \\
\text { dibasic calcium } \\
\text { phosphate } \\
\text { (mg) }\end{array}$} & \multicolumn{2}{|c|}{$\begin{array}{c}\text { HPMC } \\
\text { (Hypromellose } \\
2208 \text { K100 } \\
\text { premium) } \\
(\mathrm{mg})\end{array}$} & \multicolumn{2}{|c|}{$\begin{array}{l}\text { Microcrystal- } \\
\text { line cellulose } \\
\text { (Type- 102) } \\
\quad(\mathrm{mg})\end{array}$} & \multicolumn{2}{|c|}{$\begin{array}{l}\text { FD\&C } \\
\text { yellow } \\
6(\mathrm{mg})\end{array}$} & \multicolumn{2}{|c|}{$\begin{array}{l}\text { Magnesium } \\
\text { stearate } \\
(\mathrm{mg})\end{array}$} & \multicolumn{2}{|c|}{$\begin{array}{c}\text { Total tablet } \\
\text { weight } \\
(\mathrm{mg})\end{array}$} \\
\hline & $\begin{array}{l}\text { Qty/ } \\
\text { Tab }\end{array}$ & $\%$ & $\begin{array}{l}\text { Qty/ } \\
\text { Tab }\end{array}$ & $\%$ & $\begin{array}{l}\text { Qty/ } \\
\text { Tab }\end{array}$ & $\%$ & $\begin{array}{l}\text { Qty/ } \\
\text { Tab }\end{array}$ & $\%$ & $\begin{array}{l}\text { Qty/ } \\
\text { Tab }\end{array}$ & $\%$ & $\begin{array}{l}\text { Qty/ } \\
\text { Tab }\end{array}$ & $\%$ & $\begin{array}{l}\text { Qty/ } \\
\text { Tab }\end{array}$ & $\%$ \\
\hline AMF1 & 13.8 & 9.2 & 20 & 13.33 & 7.5 & 5 & 107.05 & 71.37 & 0.15 & 0.1 & 1.50 & 1 & 150 & 100 \\
\hline AMF2 & 13.8 & 9.2 & 20 & 13.33 & 15 & 10 & 99.55 & 66.37 & 0.15 & 0.1 & 1.50 & 1 & 150 & 100 \\
\hline AMF3 & 13.8 & 9.2 & 20 & 13.33 & 22.5 & 15 & 92.05 & 61.37 & 0.15 & 0.1 & 1.50 & 1 & 150 & 100 \\
\hline AMF4 & 13.8 & 9.2 & 20 & 13.33 & 30 & 20 & 84.55 & 56.37 & 0.15 & 0.1 & 1.50 & 1 & 150 & 100 \\
\hline AMF5 & 13.8 & 9.2 & 20 & 13.33 & 37.5 & 25 & 74.55 & 49.70 & 0.15 & 0.1 & 1.50 & 1 & 150 & 100 \\
\hline
\end{tabular}

Sustained release layer of amlodipine (AMF1AMF5) were prepared by direct compression method following the formulation given in table 2 . Amlodipine and microcrystalline cellulose (Type102) were sieved through \#30 mesh and added to a polybag and mixed for $1 \mathrm{~min} \&$ transfer into blender. Rest quantity of microcrystalline cellulose and FD\&C Yellow 6 were sieved through \#60 mesh and added to the blender. HPMC and anhydrous dibasic calcium phosphate were mixed and sieved through \#30 mesh and added to blender. The mixer then blended at $15 \mathrm{rpm}$ for 15 minutes. Magnesium stearate was sieved through \#60 mesh and added to the blender and blended at $15 \mathrm{rpm}$ for 5 minutes. Then the granules were compressed into tablets. The physicochemical parameters of amlodipine tablets (e.g. weight variation, friability, diameter, thickness, hardness and disintegration time) were measured (Ryakala et al., 2015).

In vitro evaluation of immediate release atenolol tablets: A standard curve of atenolol was prepared for determining the drug release pattern. Precisely 10 $\mathrm{mg}$ of atenolol was dissolved in $100 \mathrm{ml}$ of $0.1 \mathrm{~N} \mathrm{HCl}$ into a $100 \mathrm{ml}$ dried and clean volumetric flask. The standard drug solution was prepared that containing $100 \mu \mathrm{g} / \mathrm{ml}$ of atenolol. Next the standard drug solution was further diluted by $0.1 \mathrm{~N} \mathrm{HCl}$ to make it $2,4,5,6,7,8,10,12 \mu \mathrm{g} / \mathrm{ml}$ solution. The wavelength of maximum absorbance $\left(\lambda_{\max }\right)$ of the drug was determined by using UV-spectrophotometer in the wavelength range of $224 \mathrm{~nm}$ using $0.1 \mathrm{~N} \mathrm{HCl}$ as a blank. Dissolution rate of the prepared tablets were studied in $0.1 \mathrm{~N} \mathrm{HCl}(900 \mathrm{ml})$ medium using USP dissolution apparatus II with a paddle stirrer at 50 rpm. One tablet containing $50 \mathrm{mg}$ of atenolol was used in each test. A temperature of $37 \pm 1^{\circ} \mathrm{C}$ was maintained during the test. Samples of dissolution medium $(5 \mathrm{ml})$ were pulled out and filtered through a filter of $0.45 \mu \mathrm{m}$ size at specific time intervals and assayed for the presence of atenolol by measuring the absorbance at $224 \mathrm{~nm}$ (Bari et al., 2010).

In vitro evaluation of sustained release amlodipine tablets: A standard curve was prepared for determining the concentration of drug release 
pattern of amlodipine. Precisely $13.8 \mathrm{mg}$ amlodipine besylate equivalent to $10 \mathrm{mg}$ of amlodipine was dissolved into $100 \mathrm{ml}$ of $0.1 \mathrm{~N} \mathrm{HCl}$ in a $100 \mathrm{ml}$ dried and clean volumetric flask obtaining $100 \mu \mathrm{g} / \mathrm{ml}$ of amlodipine standard solution. Then the standard drug solution was further diluted by $0.1 \mathrm{~N} \mathrm{HCl}$ to make it $5,10,15,20,25,30,35,40 \mu \mathrm{g} / \mathrm{ml}$ solution. The wavelength of maximum absorbance $\left(\lambda_{\max }\right)$ of the drug was found at $238 \mathrm{~nm}$ by using UVspectrophotometer in $0.1 \mathrm{~N} \mathrm{HCl}$ as a blank. Same procedure was followed for preparing another standard curve of amlodipine using phosphate buffer solution. Dissolution rate of the prepared tablets were studied in $0.1 \mathrm{~N} \mathrm{HCl}$ for 2 hours followed by phosphate buffer of $\mathrm{pH} 6.8$ by using USP Dissolution Apparatus II with a paddle stirrer at $50 \mathrm{rpm}$ up to 24 hours. One tablet containing $10 \mathrm{mg}$ of amlodipine was used in each test. A temperature of $37 \pm 1^{\circ} \mathrm{C}$ was maintained during the test. Samples of dissolution medium $(5 \mathrm{ml})$ were pulled out and filtered through a filter of $0.45 \mu \mathrm{m}$ size at specific time intervals and assayed for the presence of amlodipine by measuring the absorbance at $238 \mathrm{~nm}$ (Naveed et al., 2014).

Preparation of atenolol and amlodipine bilayer tablets: For preparing bilayer tablets, the dissolution test was conducted for both layers of immediate release and sustain release separately with the aim of selecting the best formulations. Based on dissolution behavior, formulations were selected for bilayer tablet preparation. Sustain release amlodipine layer was placed in the die cavity and punched with low compression force. Then the immediate release atenolol layer was placed in the die cavity and allowed for punching with optimum hardness of 6-8 $\mathrm{kg} / \mathrm{cm}^{2}$ to form bilayer tablets. Compression was made by using $8 \mathrm{~mm}$ punches. The total weight of each bilayer tablet was adjusted to $300 \mathrm{mg}$, containing $50 \mathrm{mg}$ of atenolol in immediate release layer and $13.8 \mathrm{mg}$ of amlodipine besilate equivalent to $10 \mathrm{mg}$ of amlodipine in sustain release layer which was tabulated in table 3. Prepared bilayer tablets were evaluated for various post-compression parameters and in vitro dissolution studies (Ryakala et al., 2015).

Table 3. Formulation of atenolol and amlodipine bilayer tablets.

\begin{tabular}{lc}
\hline API / Excipients & $\begin{array}{c}\text { Amount } \\
(\mathrm{mg})\end{array}$ \\
\hline Atenolol & 50.0 \\
Amlodipine besylate & 13.80 \\
Microcrystalline cellulose Type-101 & 86.5 \\
Microcry-stalline cellulose Type-102 & 92.05 \\
Povidone K-30 & 4.5 \\
Sodium starch glycolate & 7.5 \\
Anhydrous dibasic calcium phosphate & 20.00 \\
HPMC (Hypromellose 2208 K100 & 22.50 \\
Premium) & 3.00 \\
Magnesium stearate & 0.15 \\
FD\&C Yellow 6 & 300.00 \\
\hline Total weight & \\
\hline
\end{tabular}

Physical evaluation of bilayer tablets; Formulated bilayer tablets were subjected to various evaluation tests like thickness, hardness, weight variation and friability. Thickness of the tablets was determined by using Vernier calipers. Randomly 10 tablets were selected and used for determination of thickness. Hardness is the tablet crushing strength and it is the force required to break a tablet diametrically. Hardness of tablets was measured by selecting 10 tablets randomly and the hardness of each tablet was measured with Erweka Hardness Tester. For the study of weight variation, individual weight of 20 tablets was taken. Then their average weight and their mean and standard deviation were calculated and compared with the standards. The weight of the tablet being made was measured to ensure that it contains predetermined amount of drug. The tablet friability is a measure of loss due to abrasion. Initially 10 tablets were weighed (W1) and machine was rotate at $25 \mathrm{rpm}$ for 4 minutes. After removal of fines the tablets were again weighed (W2) and the percentage of weight loss was calculated by the following equation (Ryakala et al., 2015):

Friability $=\frac{\text { Weight of tablet before testing }(\mathrm{W} 1)-\text { Weight of tablet after testing (W2) }}{\text { Weight of tablet before testing }(\mathrm{W} 1)} \times 100(\%)$ 
Evaluation of drug release from bilayer tablets: Drug release data from the optimized tablet formulation was evaluated in HPLC. Parameters used for both atenolol and amlodipine are tabulated in table 4.

Kinetic data analysis: The drug release kinetic studies were carried out for bilayer tablets of atenolol and amlodipine and were evaluated using the linear regression method:

(1) Zero order kinetic model - cumulative \% of drug released versus time $(T)$;
(2) First order kinetic model - log cumulative percent drug remaining versus time $(T)$;

(3) Higuchi's model - cumulative percent drug released versus square root of time $(T)$;

(4) Korsmeyer-Peppas model - log cumulative percent drug released versus log time $(T)$ and

(5) Hixson-Crowell model - Cube root of initial amount - Cube root of drug remaining versus time (T) (Ryakala et al., 2015).

Table 4. HPLC parameters for evaluation of atenolol and amlodipine bilayer tablets.

\begin{tabular}{|c|c|c|}
\hline HPLC parameter & Atenolol & Amlodipine \\
\hline Mobile phase & $\begin{array}{l}\text { Ammonium acetate buffer } \\
\text { Aceteritrile-Methanol }(35: 30: 35)\end{array}$ & $\begin{array}{l}\text { Ammonium acetate buffer Aceteritrile- } \\
\text { Methanol }(35: 30: 35)\end{array}$ \\
\hline Injection volume & $100 \mu \mathrm{l}$ & $100 \mu \mathrm{l}$ \\
\hline Column temperature & $40{ }^{\circ} \mathrm{C}$ & $40{ }^{\circ} \mathrm{C}$ \\
\hline Flow rate & $1.0 \mathrm{ml} / \mathrm{min}$ & $1.0 \mathrm{ml} / \mathrm{min}$ \\
\hline Name of standard & Atenolol BP/Ph. Euro. WS & Amlodipine BP/Ph. Euro. WS \\
\hline Standard potency & 99.4 & 100.0 \\
\hline Column & $\begin{array}{l}\text { YMC-Pack Pro C18, } \\
300 \mathrm{~mm} \times 4.6 \mathrm{~mm}, 5 \mu\end{array}$ & $\begin{array}{l}\text { YMC-Pack Pro C18, } \\
300 \mathrm{~mm} \times 4.6 \mathrm{~mm}, 5 \mu\end{array}$ \\
\hline Detector (UV type) & $224 \mathrm{~nm}$ & $238 \mathrm{~nm}$ \\
\hline
\end{tabular}

\section{Results and Discussion}

\section{Drug-drug and drug-excipient compatibility} studies

Compatibility studies by physical observation in stability chamber: The drug-drug and drug-excipient samples were collected from stability chamber after one month. Any change in physical appearance and odor was investigated. In all individuals and combinations at room condition $\left(25{ }^{\circ} \mathrm{C} \pm 2{ }^{\circ} \mathrm{C}\right.$ \& $60 \% \pm 5 \% \mathrm{RH})$ were complies with specification while most of the combination showed sensitivity (e.g. discoloration, bad odor and lump formation) at accelerated open condition $\left(40{ }^{\circ} \mathrm{C} \pm 2{ }^{\circ} \mathrm{C} \& 75 \% \pm\right.$ $5 \% \mathrm{RH})$, while only Atenolol: Povidone K-30 and Amlodipine: Magnesium stearate $(1: 1)$ at $50{ }^{\circ} \mathrm{C}$ showed lump formation with bad odor generation.
Compatibility studies by FTIR: Same peaks were observed in drug product crushed powder which indicated that there were no polymorphic changes in the drug substance during the preparation of tablets with excipients. Furthermore, the absence of shifts in the wave numbers of the FTIR peaks of the solid dispersions compared to the physical mixture, indicates the lack of significant interaction between the drugs and excipients at the molecular level are shown in figure 1 .

Compatibility studies by DSC: Sharp endothermic peak was observed at $155.71{ }^{\circ} \mathrm{C}$ and $205.65{ }^{\circ} \mathrm{C}$ indicating the melting point of atenolol and amlodipine respectively. In formulation mixer the peak was found at $69.35{ }^{\circ} \mathrm{C}$ indicating that the formulation was stable up to $69{ }^{\circ} \mathrm{C}$. All are shown in figure 2 . 

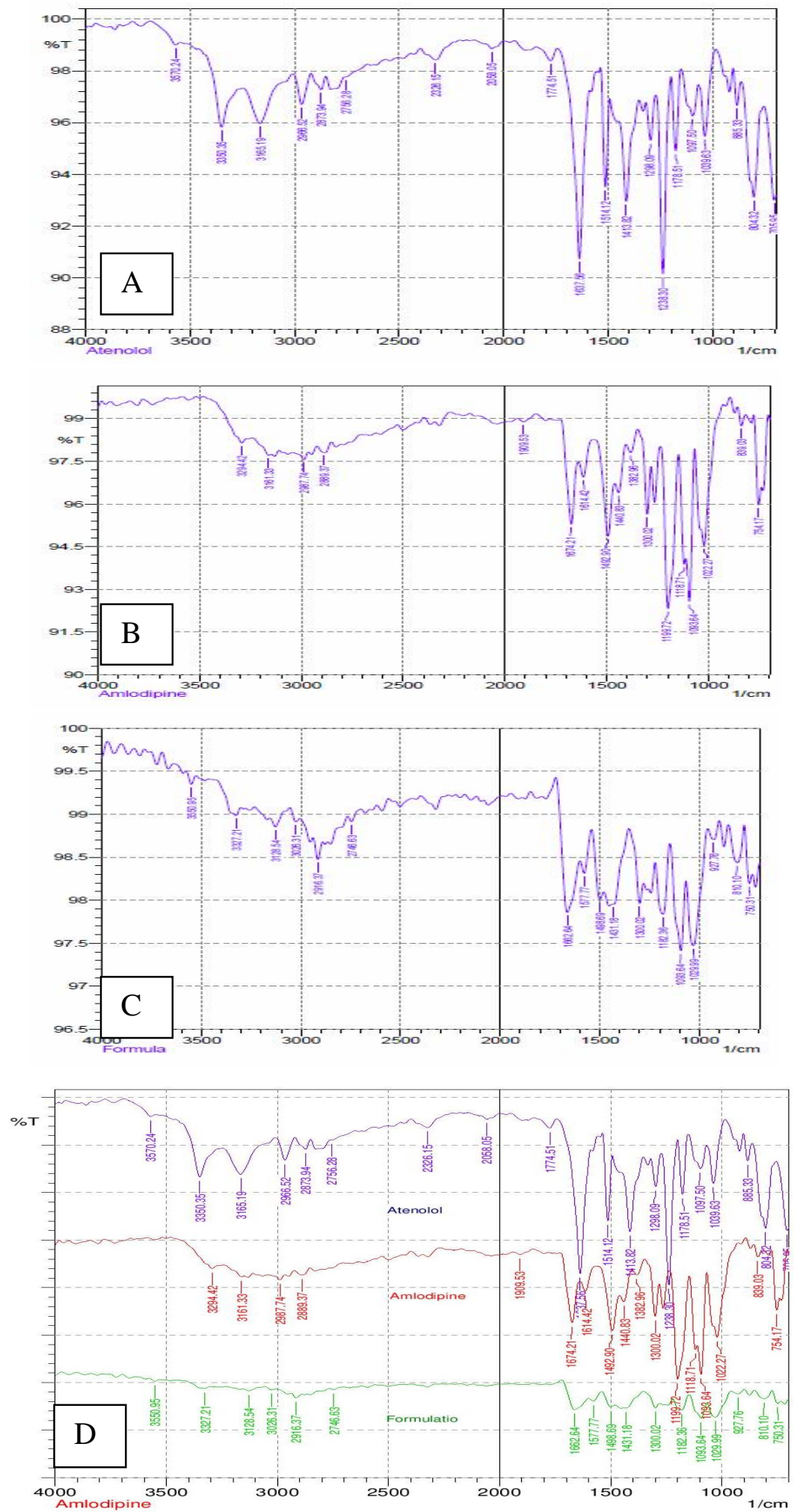

Figure 1. FTIR spectrum of (A) Atenolol pure drug, (B) amlodipine pure drug, (C) optimized formula of bilayer tablet and (D) Atenolol and amlodipine with optimized formula of bilayer tablet. 
Degree of crystallinity studies by X-RD: Peak heights of optimized tablet formulations were affected compared to pure atenolol and amlodipine indicating reduction in crystal size and crystallinity but most importantly no peaks were disappeared. Atenolol showed sharp peaks at diffraction angles at $2 \theta$ of $20.71,22.41,23.92,19.32,24.49$ and $31.93^{\circ} \mathrm{C}$, whereas, amlodipine showed sharp peaks at diffraction angles at $2 \theta$ of $11.60,24.25,19.99,23.30$ and $30.83{ }^{\circ} \mathrm{C}$. The results are shown in figure 3 .

Characterization of immediate release and sustained release granules: Flow properties of atenolol and amlodipine granules were carried out and results are shown in the tables 5 and 6 which were found as per according to United States Pharmacopocial guidelines.

Table 5. Granules characterization of atenolol formulations.

\begin{tabular}{lccccc}
\hline $\begin{array}{l}\text { Physical properties of } \\
\text { granules }\end{array}$ & ATF1 & ATF2 & ATF3 & ATF4 & ATF5 \\
\hline LOD & 2.11 & 1.90 & 2.04 & 1.87 & 1.66 \\
Bulk density $\left(\mathrm{gm} / \mathrm{cm}^{3}\right)$ & 0.59 & 0.56 & 0.60 & 0.54 & 0.55 \\
Tapped density $\left(\mathrm{gm} / \mathrm{cm}^{3}\right)$ & 0.68 & 0.73 & 0.68 & 0.71 & 0.71 \\
Hausner's ratio & 1.10 & 1.29 & 1.14 & 1.31 & 1.29 \\
Carr's index (\%) & 13.24 & 23.29 & 11.76 & 23.94 & 22.54 \\
Angle of repose & 32.3 & 43.1 & 34.6 & 41.7 & 44.2 \\
Granules flow property & Good & Passable & Good & Passable & Passable \\
\hline
\end{tabular}

Table 6. Granules characterization of amlodipine formulations.

\begin{tabular}{lccccc}
\hline Physical properties of granules & AMF1 & AMF2 & AMF3 & AMF4 & AMF5 \\
\hline Bulk density $\left(\mathrm{gm} / \mathrm{cm}^{3}\right)$ & 0.50 & 0.43 & 0.43 & 0.43 & 0.43 \\
Tapped density $\left(\mathrm{gm} / \mathrm{cm}^{3}\right)$ & 0.63 & 0.55 & 0.55 & 0.55 & 0.55 \\
Hausner's ratio & 1.25 & 1.27 & 1.27 & 1.27 & 1.27 \\
Carr's index (\%) & 20.63 & 21.82 & 21.82 & 21.82 & 21.82 \\
Angle of repose & 33.4 & 42.8 & 35.0 & 44.7 & 42.8 \\
Granules Flow Property & Good & Passable & Good & Passable & Passable \\
\hline
\end{tabular}

Table 7. Data for calibration curve of Atenolol in $0.1 \mathrm{~N} \mathrm{HCl}$.

\begin{tabular}{lc}
\hline Concentration $(\mu \mathrm{g} / \mathrm{ml})$ & Absorbance \\
\hline 2 & 0.124 \\
4 & 0.162 \\
5 & 0.181 \\
6 & 0.20 \\
7 & 0.219 \\
8 & 0.238 \\
10 & 0.274 \\
12 & 0.304 \\
\hline
\end{tabular}



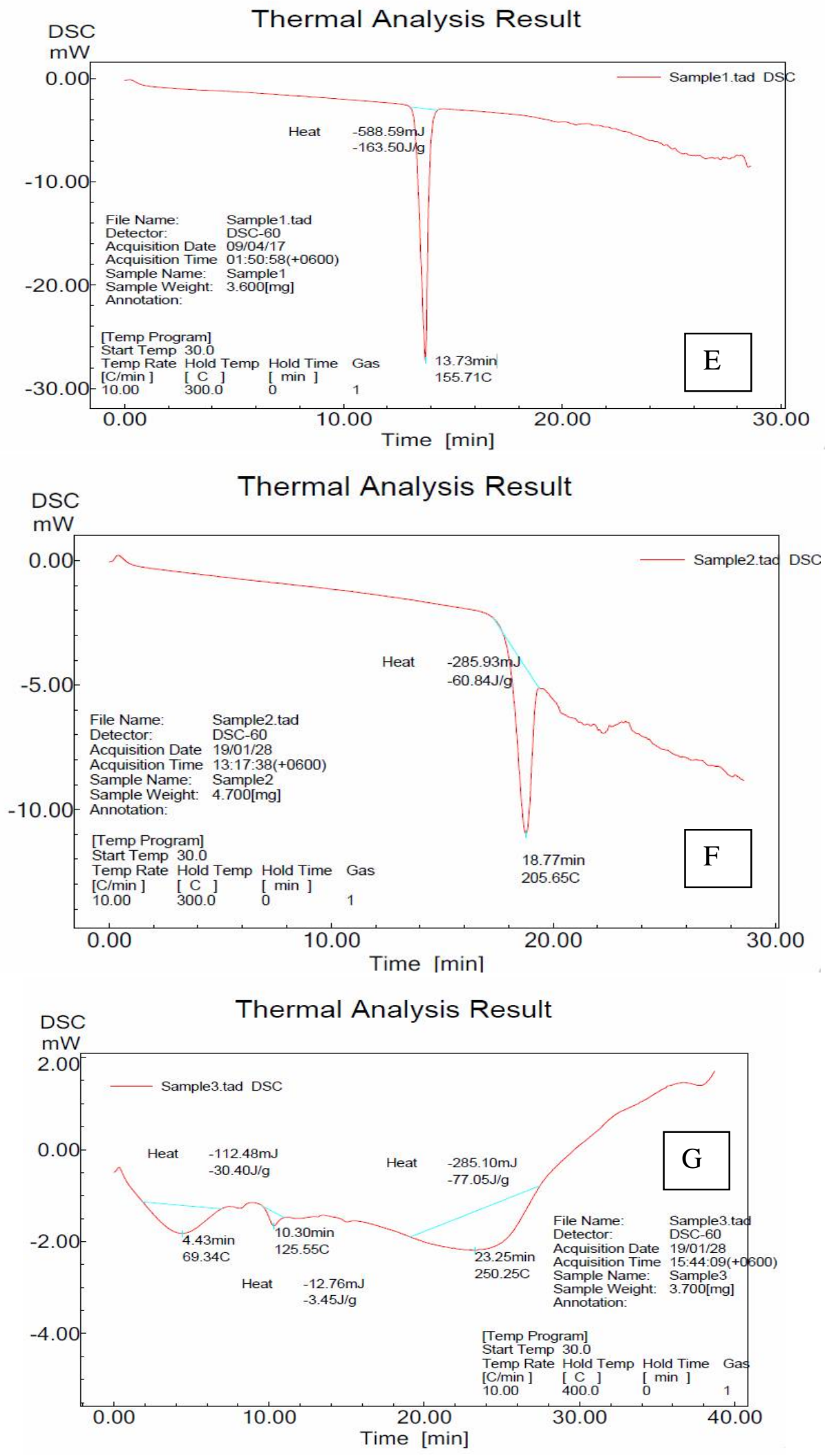

Figure 2. DSC thermogram of (E) pure atenolol, (F) pure amlodipine and (G) optimized formulation mixer. 

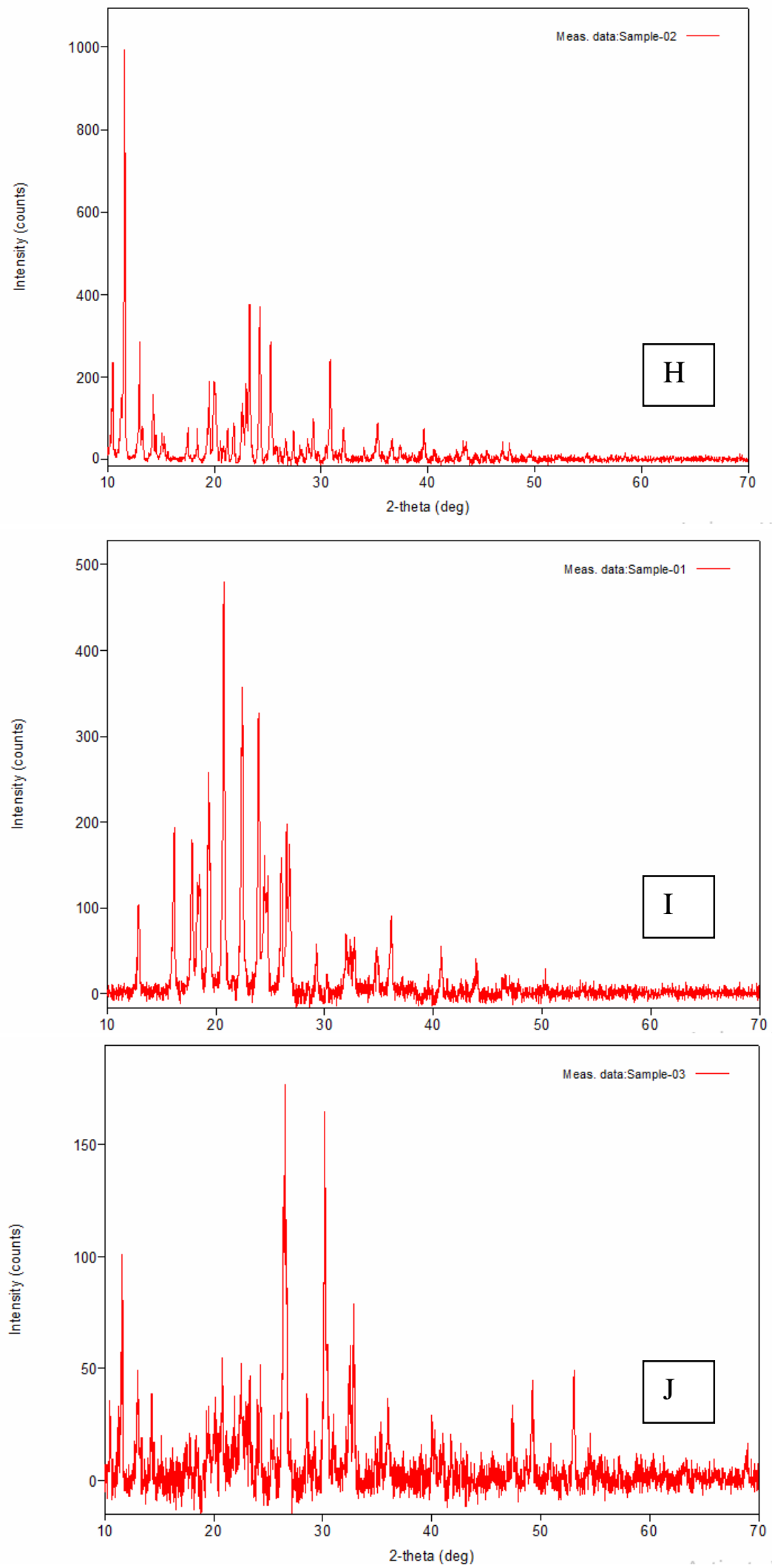

Figure 3. X-RD of (H) pure atenolol, (I) pure amlodipine and (J) crushed tablet. 
Evaluation of atenolol IR and amlodipine SR tablets: Calibration curves were plotted for both atenolol and amlodipine based on the data obtained in UV-Spectrophotometer are represented in tables 7 and 8 and in figure 4 (a) and (b).

The prepared formulations of atenolol were evaluated for post-compression parameters and the results of all formulations were reported in table 9. formulation batches ATF1-ATF5 have shown an immediate release profile between 94.45 and $99.87 \%$ within 45 minutes where ATF1 showed highest percent of drug release (99.87\%) after 45 minutes. From that above data, formulation ATF1 was optimized for bilayer tablet as it reflected good disintegration and dissolution characteristics. These results are represented in table 11 .

After carrying out in-vitro drug release studies,

Table 8. Data for calibration curve of Amlodipine in 0.1 N HCL and pH 6.8 phosphate buffer.

\begin{tabular}{lcc}
\hline \multirow{2}{*}{ Concentration $(\mu \mathrm{g} / \mathrm{ml})$} & \multicolumn{2}{c}{ Absorbance } \\
\cline { 2 - 3 } & $0.1 \mathrm{~N} \mathrm{HCL}$ & $\mathrm{pH} 6.8$ Phosphate buffer \\
\hline 5 & 0.051 & 0.048 \\
10 & 0.111 & 0.103 \\
15 & 0.162 & 0.158 \\
20 & 0.201 & 0.213 \\
25 & 0.276 & 0.268 \\
30 & 0.311 & 0.331 \\
35 & 0.355 & 0.368 \\
40 & 0.399 & 0.423 \\
\hline
\end{tabular}

\section{Calibration curve of Atenolol}

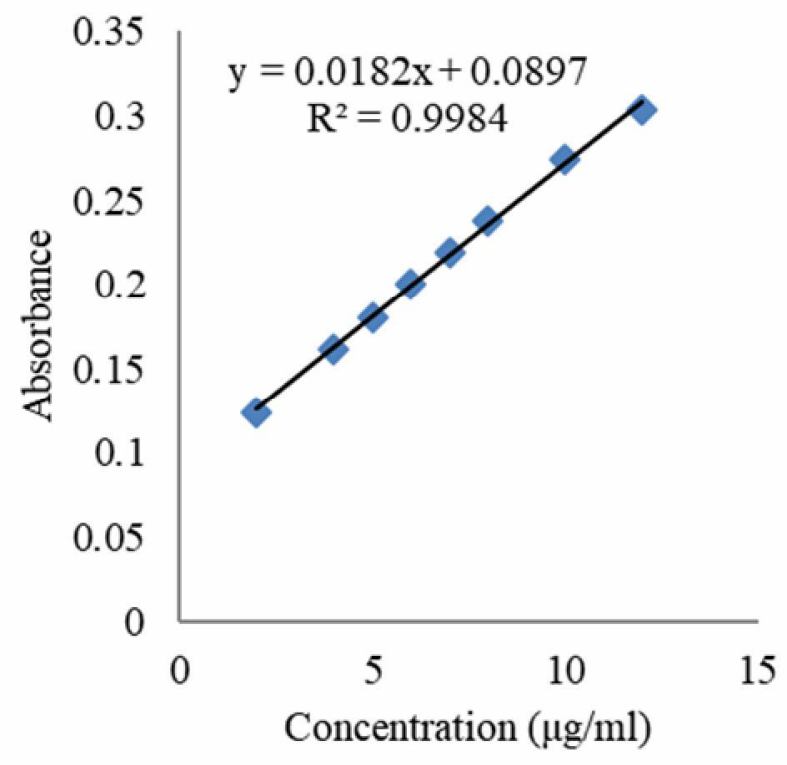

Figure 4 (a). Calibration curve of atenolol in $0.1 \mathrm{~N} \mathrm{HCL}$. 

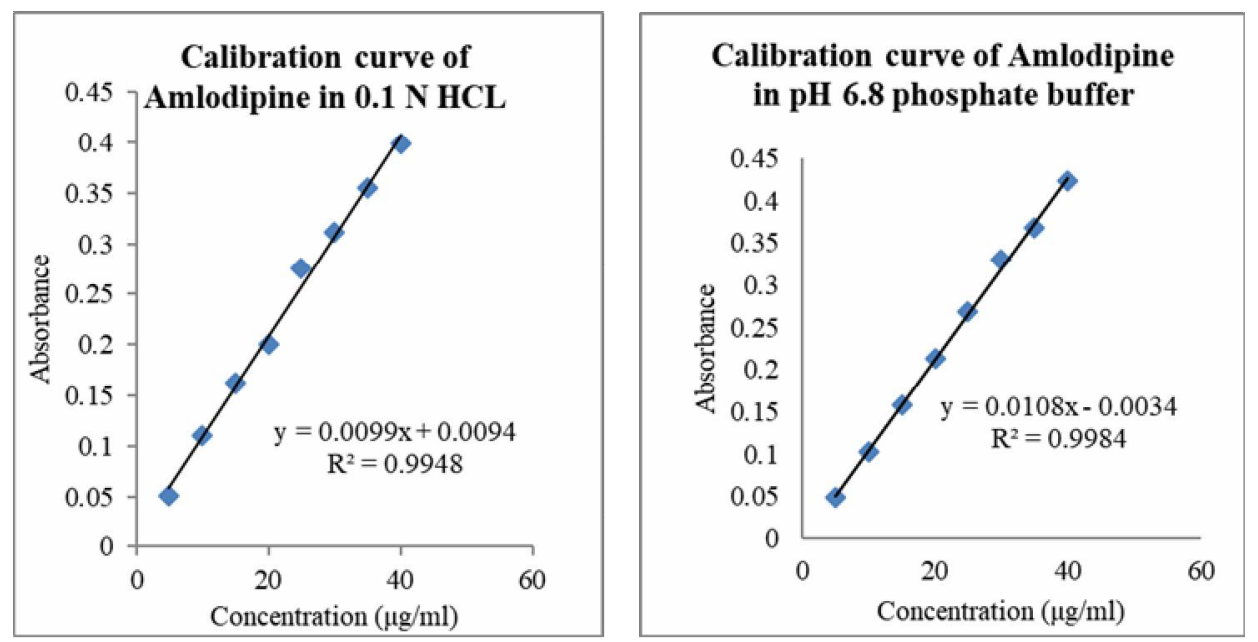

Figure 4 (b). Calibration curve of amlodipine in 0.1 N HCL and pH 6.8 phosphate buffer.

Table 9. Evaluation of physical properties of atenolol immediate release tablets.

\begin{tabular}{lccccc}
\hline Physical properties of tablets & ATF1 & ATF2 & ATF3 & ATF4 & ATF5 \\
\hline Average tablet weight $(\mathrm{mg})$ & 153 & 151 & 150 & 149 & 153 \\
Thickness (mm) & 3.10 & 3.09 & 3.07 & 3.07 & 3.09 \\
Diameter (mm) & 8.07 & 8.04 & 4.03 & 8.07 & 8.05 \\
Hardness (Kg/cm $\left.{ }^{2}\right)$ & 4.71 & 4.78 & 0.17 & 4.87 & 4.95 \\
Friability (\%) & 0.23 & 0.22 & $1 \mathrm{~min} 20 \mathrm{sec}$ & $1 \mathrm{~min}$ & $1 \mathrm{~min} 10 \mathrm{sec}$ \\
Disintegration time & $45 \mathrm{sec}$ & $20 \mathrm{sec}$ & & & \\
\hline
\end{tabular}

Table 10. Evaluation of physical properties of amlodipine sustained release tablets.

\begin{tabular}{lccccc}
\hline $\begin{array}{l}\text { Physical properties of } \\
\text { tablets }\end{array}$ & AMF1 & AMF2 & AMF3 & AMF4 & AMF5 \\
\hline $\begin{array}{l}\text { Average tablet weight } \\
(\mathrm{mg})\end{array}$ & 153 & 150 & 153 & 155 & 155 \\
Thickness $(\mathrm{mm})$ & 3.05 & 3.02 & 3.03 & 3.04 & 3.03 \\
Diameter $(\mathrm{mm})$ & 8.06 & 8.09 & 8.06 & 8.09 & 8.04 \\
Hardness $\left(\mathrm{Kg} / \mathrm{cm}^{2}\right)$ & 5.38 & 5.90 & 5.29 & 5.35 & 5.99 \\
Friability $(\%)$ & 0.29 & 0.35 & 0.17 & 0.41 & 0.39 \\
\hline
\end{tabular}

Table 11. In-vitro drug release data of atenolol immediate release tablets.

\begin{tabular}{cccccc}
\hline \multirow{2}{*}{$\begin{array}{c}\text { Time points } \\
(\mathrm{min})\end{array}$} & ATF1 & ATF2 & ATF3 Drug released & ATF4 & ATF5 \\
\cline { 2 - 6 } & 0 & 0 & 0 & 0 & 0 \\
5 & 52.34 & 55.02 & 41.51 & 49.11 & 44.61 \\
10 & 76.41 & 79.35 & 68.47 & 64.38 & 59.9 \\
15 & 89.47 & 96.51 & 89.23 & 93.18 & 73.24 \\
20 & 95.24 & 98.41 & 94.1 & 94.52 & 83.89 \\
30 & 98.45 & 99.32 & 97.02 & 95.74 & 88.76 \\
45 & 99.87 & 99.64 & 98.32 & 98.54 & 94.45 \\
\hline
\end{tabular}


Table 12. In-vitro drug release data of amlodipine sustained release tablets.

\begin{tabular}{cccccc}
\hline \multirow{2}{*}{$\begin{array}{c}\text { Time points } \\
\text { (hour) }\end{array}$} & AMF1 & AMF2 & AMF3 & AMF4 & AMF5 \\
\cline { 2 - 5 } & 24.78 & 14.21 & 8.1 & 8.12 & 6.16 \\
01 & 49.54 & 26.89 & 14.25 & 21.07 & 14.28 \\
05 & 91.65 & 68.52 & 36.87 & 38.28 & 29.42 \\
08 & 99.84 & 88.43 & 60.65 & 70.88 & 60.85 \\
12 & 99.88 & 98.32 & 87.54 & 77.95 & 71.87 \\
24 & 99.95 & 99.90 & 99.98 & 88.54 & 84.36 \\
\hline
\end{tabular}

Post-compression parameters were evaluated for all the formulations of amlodipine and results were shown in table 10. After performing in-vitro drug release studies, formulation batches AMF1-AMF5 had shown a sustained release profile between 84.36 and $99.98 \%$ after 24 hours where AMF3 showed
$99.98 \%$ of drug release which was the highest percent of drug release after 24 hours. So, AMF3 was optimized for bilayer tablet as it showed good disintegration and drug release characteristics. The results are showed in table 12.

Table 13. Evaluation of physical properties of bilayer tablets.

\begin{tabular}{lccccc}
\hline Name & $\begin{array}{c}\text { Weight variation } \\
(\%)\end{array}$ & $\begin{array}{c}\text { Hardness } \\
\left(\mathrm{Kg} / \mathrm{cm}^{2}\right)\end{array}$ & Thickness $(\mathrm{mm})$ & Diameter $(\mathrm{mm})$ & $\begin{array}{c}\text { Friability } \\
(\%)\end{array}$ \\
\hline Bilayer tablet & 0.56 & 5.38 & 5.93 & 8.06 & 0.24 \\
\hline
\end{tabular}

Table 14. In-vitro drug release data by HPLC of atenolol immediate release and amlodipine sustained release bilayer tablets.

\begin{tabular}{lcc}
\hline Time & \% Drug Release of Atenolol (ATF1) & \% Drug Release of Amlodipine (AMF3) \\
\hline $05 \mathrm{~min}$ & 47.05 & - \\
$10 \mathrm{~min}$ & 63.66 & - \\
$15 \mathrm{~min}$ & 91.93 & - \\
$20 \mathrm{~min}$ & 93.18 & - \\
$30 \mathrm{~min}$ & 95.64 & - \\
$45 \mathrm{~min}$ & 98.95 & - \\
01 hour & - & 11.34 \\
02 hour & - & 18.55 \\
05 hour & - & 37.12 \\
08 hour & - & 62.89 \\
12 hour & - & 86.54 \\
24 hour & - & 98.12 \\
\hline
\end{tabular}

Table 15. Release profiles of atenolol (ATF1) and amlodpine (AMF3) from bilayer tablets in various models.

\begin{tabular}{|c|c|c|c|c|c|c|c|c|c|c|}
\hline \multirow[t]{2}{*}{ Drug } & \multicolumn{2}{|c|}{ Zero order } & \multicolumn{2}{|c|}{ First order } & \multicolumn{2}{|c|}{ Higuchi } & \multicolumn{2}{|c|}{$\begin{array}{c}\text { Korsmeyar- } \\
\text { Peppas }\end{array}$} & \multicolumn{2}{|c|}{ Hixson-Croswell } \\
\hline & $\mathrm{K}_{0}$ & $\mathrm{R}^{2}$ & $\mathrm{~K}_{1}$ & $\mathrm{R}^{2}$ & $\mathrm{~K}_{\mathrm{h}}$ & $\mathrm{R}^{2}$ & $\mathrm{n}$ & $\mathrm{R}^{2}$ & $\mathrm{~K}_{\mathrm{HC}}$ & $\mathrm{R}^{2}$ \\
\hline ATF1 & 111.3 & 0.62 & -2.6 & 0.94 & 120.4 & 0.88 & 0.35 & 0.84 & 3.87 & 0.81 \\
\hline AMF3 & 4.2 & 0.86 & -0.07 & 0.99 & 22.72 & 0.95 & 0.73 & 0.97 & 0.15 & 0.97 \\
\hline
\end{tabular}



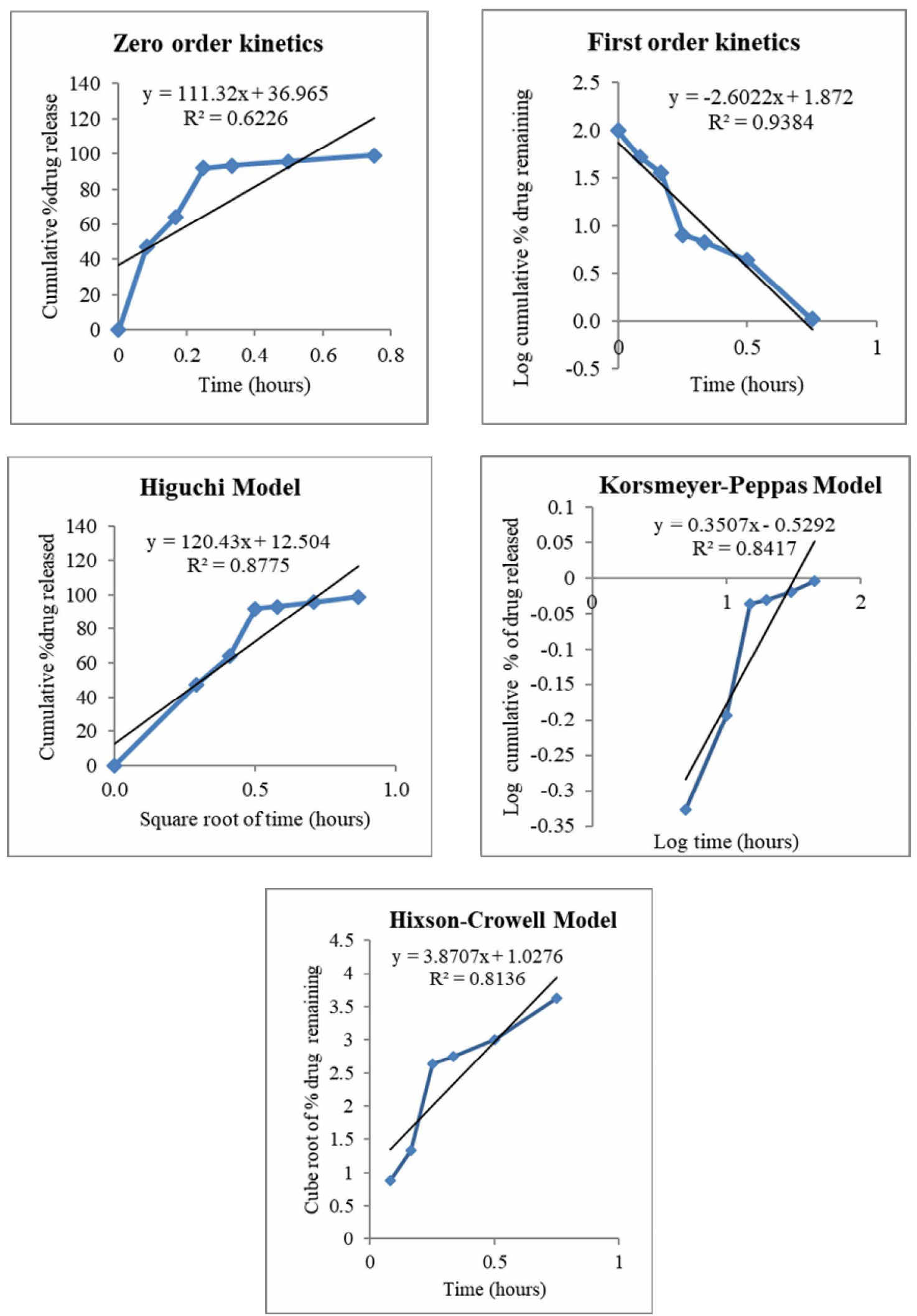

Figure 5. Drug release kinetics of atenolol (immediate release) layer in bilayer tablet. 

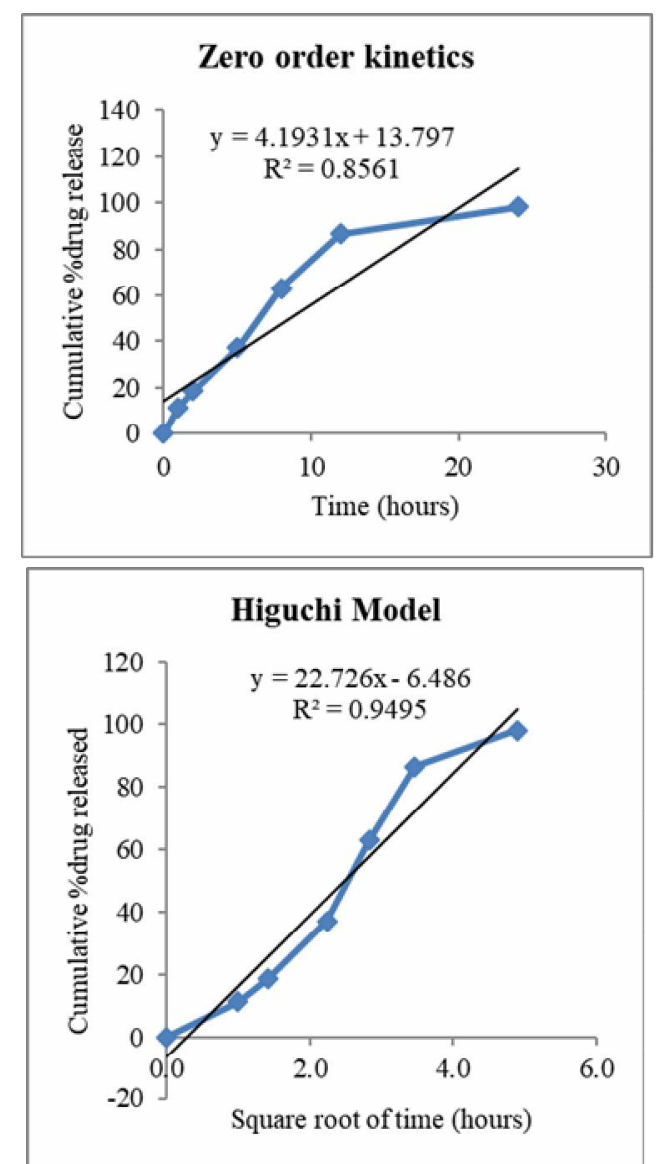

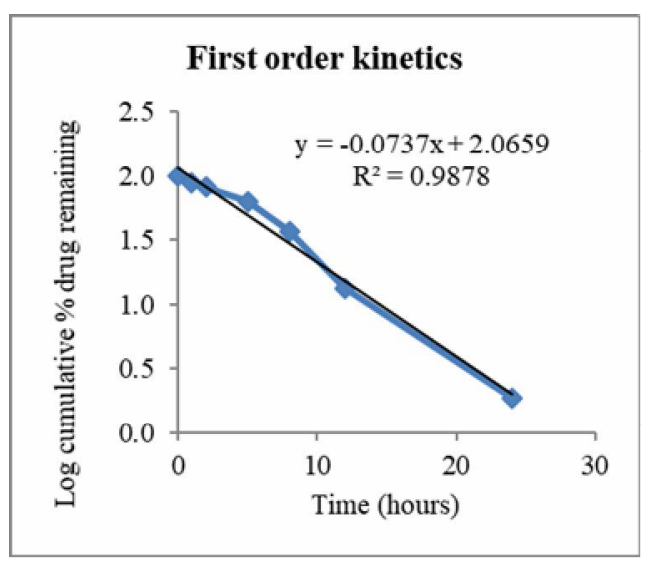

Korsmeyar-Peppas model

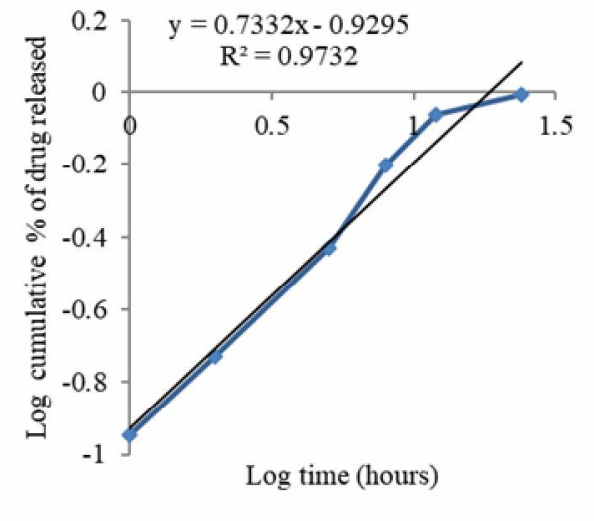

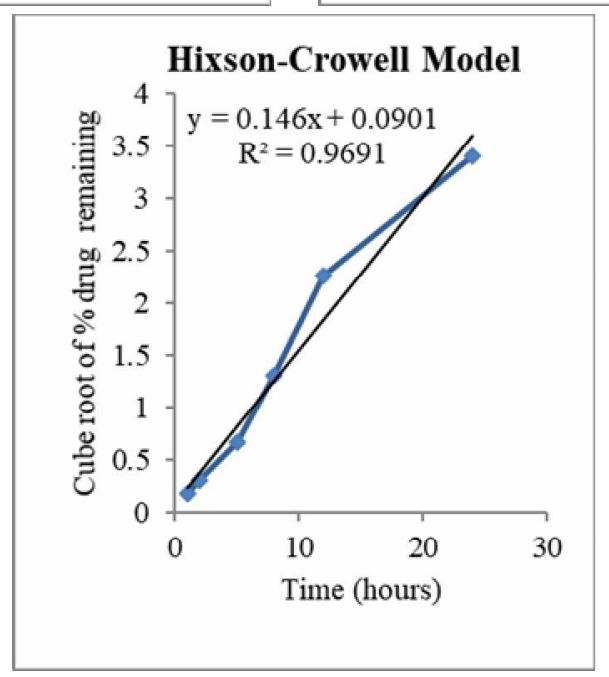

Figure 6. Drug release kinetics of amlodipine (sustained release) layer in bilayer tablet.

Evaluation of bilayer tablets: Bilayer tablets were prepared successfully after selecting the optimized formulations of immediate release layer (ATF1) and sustained release layer (AMF3). The prepared bilayer tablets were evaluated for post- compression parameters and results were found to be within the limits were shown in table 13. In-vitro drug release studies of bilayer tablets were carried out by HPLC are shown in table 14. From the results, drug release of atenolol immediate release layer was 
found $98.95 \%$ in 45 minutes and that of the amlodipine sustained release layer was $98.12 \%$ at the end of 24 hours and percent drug release of amlodipine after first hour was found only $11.34 \%$. It implies that the release of sustained release drug in the medium preferred for immediate release layer was found to be negligible and thus showed no irregularities in the drug release of bilayer tablet.

Kinetics data analysis: Drug release kinetics data of atenolol layer is shown in table 15 and graphs are represented in figures 5 and 6. From the graphical representations, it can be understood that atenolol layer was best fitted to the first order kinetics model which showed a regression coefficient $\left(5^{2}\right)$ of 0.94 whereas amlodipine layer was also best fitted to the first order kinetics that showed a regression coefficient $\left(5^{2}\right)$ of 0.99 . Korsemeyer-Peppas equation was used to analyze the release pattern of the drug from the polymeric system. For atenolol layer the value of "5" was found 0.35 which was less than 0.45, indicating the drug release followed Case I, QasiFickian transport and the value of " 5 " was found for amlodipine layer was 0.73 which was less than 0.89 but more than 0.45 , indicating the drug release followed Anomalous (non-Fickian) transport (Bithi et al., 2017).

\section{Conclusions}

The present study demonstrated the successful formulation and evaluation of two antihypertensive agents in a single dosage form as bilayer tablet. In the bilayer tablet, ATF1 was the optimized formulations of atenolol for the immediate release layer containing sodium starch glycolate as super-disintegrant and AMF3 was the optimized amlodipine sustained release layer containing HPMC. The compatibility studies carried out using by FTIR and DSC revealed that no interaction found between drugs and excipients of optimized was bilayer tablets. All the pre and post compression studies were found to be within the official limits. In-vitro drug release studies showed that release of atenolol in immediate release layer in bilayer tablet was found $98.97 \%$ after 45 minutes and amlodipine in sustained release layer was $98.12 \%$ at the end of $24 \mathrm{hrs}$. Release kinetics showed good linearity by best fitting into first order kinetics for both layers and stability studies showed no changes in room condition and closed accelerated conditions for a period of 1 month.

Thus, it can be concluded that the prepared bilayer tablets achieved the objective of the research work in treating hypertension with the sequential releases of two drugs to enhance the efficacy of the antihypertensive agents as well as to sustain the antihypertensive activity. However, further extensive studies are required to establish its suitability as antihypertensive agent.

\section{Acknowledgements}

The authors acknowledge the help of Biomedical Research Centre, University of Dhaka and Beximco Pharmaceuticals Ltd. for using their laboratories.

\section{Conflict of interest}

The authors declare no conflict of interest.

\section{References}

Bangalore, S., Kamalakkannan, G., Parkar, S. and Messerli, F.H. 2007. Fixed-dose combinations improve medication compliance: a meta-analysis. Am. J. Med. 120, 713-719.

Bari, S., Sathe, S., Jain, P. and Surana, S. 2010. Spectrophotometric method for simultaneous estimation of atenolol in combination with losartan potassium and hydrochlorothiazide in bulk and tablet formulation. J. Pharm. BioAllied Sci. 2, 372.

Bithi, F.A., Saha, T., Ahmed, N., Hasan, I. and Reza, M.S. 2017. Preparation and in-vitro evaluation of mucoadhesive tablets of montelukast sodium. Bangladesh Pharm. J. 20, 123-131.

Brown, H.C., Carruthers, S.G., Johnston, G.D., Kelly, J.G., McAinsh, J., McDevitt, D.G. and Shanks, R.G. 1976. Clinical pharmacologic observations on atenolol, a beta-adrenoceptor blocker. Clin. Pharmacol. Ther. 20, 524-534.

Charoo, N.A., Shamsher, A.A., Zidan, A.S. and Rahman, Z. 2012. Quality by design approach for formulation development: a case study of dispersible tablets. Int. J. Pharm. 423, 167-178. 
Chobanian, A.V., Bakris, G.L., Black, H.R., Cushman, W.C., Green, L.A., Izzo Jr, J.L., Jones, D.W., Materson, B.J., Oparil, S., Wright Jr, J.T. and Roccella, E.J. 2003. The seventh report of the joint national committee on prevention, detection, evaluation, and treatment of high blood pressure: the JNC 7 report J. Am. Med. Assoc. 289, 2560-2571.

Moisei, A., Gligor, F., Bojiţă, M.A., Chiş, A.D., Totan, M., Vonica-Gligor, L.A. and Ciurba, A. 2014. Compatibility and stability studies of antihypertensive/excipients by thermal methods, used in the preformulation phase. Farmaci. 62, 1239-1248.

Naveed, S., Qamar, H., Jawaid, W. and Bokhari, U. 2014. Simple UV spectrophotometric assay of Amlodipine. Am. J. Chem. Appl. 1, 66-69.

Pereira, R.N., Valente, B.R., Cruz, A.P., Foppa, T., Murakami, F.S. and Silva, M.A. 2007. Thermoanalytical study of atenolol and commercial tablets. Lat. Am. J. Pharm. 26, 382.
Ryakala, H., Dineshmohan, S., Ramesh, A. and Gupta, V.R.M. 2015. Formulation and in vitro evaluation of bilayer tablets of nebivolol hydrochloride and nateglinide for the treatment of diabetes and hypertension. J. Drug Delivery. Article ID 827859.http://dx.doi.org/10.1155/2015/827859

Silva, A.C.M., Gálico, D.A., Guerra, R.B., Perpétuo, G.L., Legendre, A.O., Rinaldo, D. and Bannach, G. 2015. Thermal stability and thermal decomposition of the antihypertensive drug amlodipine besylate. J. Therm. Anal. Calorim. 120, 889-892.

Spedding, M. and Paoletti, R. 1992. Classification of calcium channels and the sites of action of drugs modifying channel function. Pharmacol. Rev. 44, 363376.

Xu, L.P., Shen, F.M., Shu, H., Miao, C.Y., Jiang, Y.Y. and Su, D.F. 2004. Synergism of atenolol and amlodipine on lowering and stabilizing blood pressure in spontaneously hypertensive rats. Fundam. Clin. Pharmacol. 18, 33-38. 